\title{
Presenting features of polymyalgia rheumatica (PMR) and rheumatoid arthritis with PMR-like onset: a prospective study
}

\author{
R Caporali, C Montecucco, O Epis, F Bobbio-Pallavicini, T Maio, M A Cimmino
}

\begin{abstract}
Objective-To evaluate in a prospective study whether patients with polymyalgia rheumatica (PMR) and patients with rheumatoid arthritis (RA) with PMR-like onset show distinctive clinical and laboratory features.

Methods-A cohort of 116 consecutive patients with bilateral girdle pain for at least one month and raised erythrocyte sedimentation rate (ESR) was studied and followed up for 12 months. Laboratory tests included determination of ESR, IgM rheumatoid factor, haemoglobin, white blood cell count, platelet count, percentage of CD8 lymphocytes, serum aspartate aminotransferase, alanine aminotransferase, alkaline phosphatase, and glutamyltransferase concentrations.

Results-At first examination, RA was diagnosed in 22/116 (19\%) patients and PMR in 94 (81\%) patients. During the follow up period, 19 additional patients developed RA, and the diagnosis of PMR was confirmed in $65(56 \%)$ patients at the end of the study. Of the clinical and laboratory features, only the presence of peripheral synovitis could differentiate patients who will develop RA from those with "true" PMR, but the positive predictive value of this feature was poor.

Conclusion-At present, there are no clinical or routine laboratory features allowing early differentiation between PMR and RA with PMR-like onset. (Ann Rheum Dis 2001;60:1021-1024)
\end{abstract}

Accepted 25 April 2001

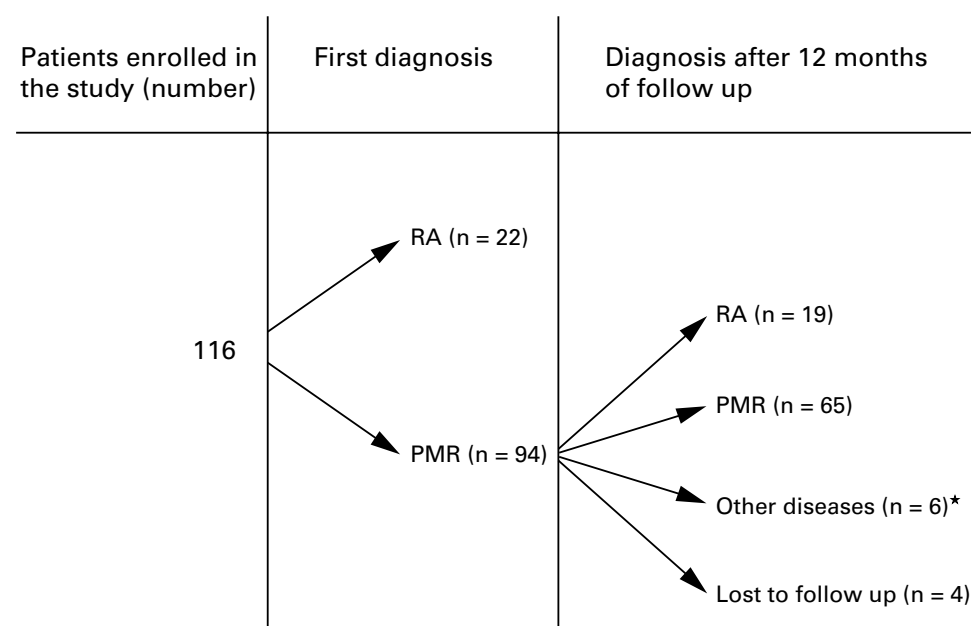

Figure 1 Diagnostic tree of the course of the disease in patients presenting with polymyalgia rheumatica (PMR)-like features, during 12 months of follow up. RA,

Rheumatoid arthritis; PMR, polymyalgia, rheumatica. Three patients with cancer and three with giant cell arteritis.
The differential diagnosis between polymyalgia rheumatica (PMR) and elderly onset rheumatoid arthritis (RA) can be difficult because these conditions may have a similar clinical presentation. Important features characterising both diseases are acute involvement of the girdles, severe morning stiffness, raised erythrocyte sedimentation rate (ESR), and a good response to low doses of prednisone. ${ }^{12}$ Elderly onset RA is characterised by peripheral arthritis, but patients with PMR may also show distal musculoskeletal manifestations. This feature occurs in $21-40 \%$ of patients with PMR according to different studies. ${ }^{3-5}$ Although some authors have suggested that RA with PMR-like onset and PMR may be the same entity, ${ }^{6}$ others have extensively studied how to differentiate these conditions by means of clinical data, HLA typing, lymphocyte subsetting, additional laboratory tests, imaging, or invasive methods. ${ }^{8-12}$ The results of these studies are not conclusive, and the topic is still debated.

Our work is concerned with a prospective study of 116 consecutive patients presenting with PMR-like symptoms in order to evaluate whether patients with PMR and patients with RA with PMR-like onset show distinctive clinical and laboratory features.

Patients and methods

We studied prospectively a cohort of 116 consecutive patients observed at our institutions. Inclusion criteria were: (a) age greater than 49 years; $(b)$ bilateral girdle pain (with or without morning stiffness) for at least one month; (c) ESR $>40 \mathrm{~mm}$ at 1 hour (Westergren). Patients with a positive ANA test $(>1 / 160$ on Hep2 cells) and/or raised serum creatine kinase concentrations were excluded from the study. Patients already treated with steroids or disease modifying anti-rheumatic drugs, with evidence of infectious diseases, neoplasms, or giant cell arteritis were also excluded.

Clinical assessment was performed by the same doctor at the first examination, monthly for the first six months, and every two months up to one year thereafter. In particular, systemic signs such as fever, weight loss, headache, and early morning stiffness were recorded. Peripheral synovitis and muscle atrophy were evaluated clinically. Laboratory tests were performed at the first visit and every two months. They included determination of ESR, IgM rheumatoid factor (RF), haemoglobin, white blood cell count, platelet count, percentage of CD8 lymphocytes (performed in 49 patients), serum aspartate aminotransferase, 


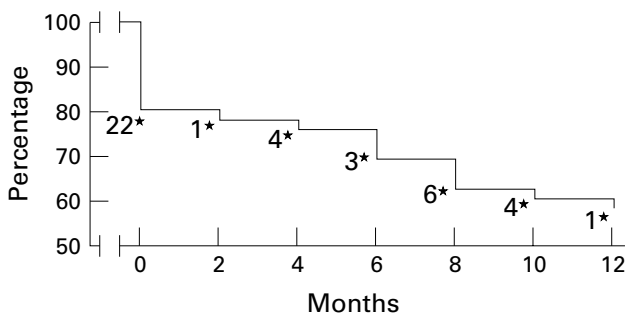

Figure 2 Kaplan-Meier curve showing the percentage of patients presenting with polymyalgia rheumatica $(P M R)$-like features $(n=116)$ whose diagnosis remained PMR during a one year follow up. ${ }^{\star}$ Number of patients with a new diagnosis of rheumatoid arthritis.

alanine aminotransferase, alkaline phosphatase, and glutamyltransferase concentrations. RA was diagnosed according to the 1987 ACR (formerly ARA) criteria, ${ }^{13}$ and PMR was diagnosed as described by Jones and Hazleman. ${ }^{14}$ An $x$ ray examination of hands and wrists was performed at the first examination, after six months, and at the end of the study; clinical and laboratory criteria were checked at each examination. The study was discontinued after 12 months. After the first examination, patients not fulfilling the ACR criteria for RA were treated with prednisone alone at an initial dose of $17.5 \mathrm{mg} /$ day. Prednisone was than tapered to achieve a maintenance dose of 5 $\mathrm{mg}$ /day after eight months. Patients with a diagnosis of RA were treated and followed according to standard clinical guidelines and were not considered for final evaluation.

\section{STATISTICAL ANALYSIS}

Differences between groups were evaluated using the non-parametric Mann-Whitney test for continuous variables and the $\chi^{2}$ test with continuity correction for categorical variables.

Table 1 Main clinical features in the two groups of patients, divided according to the final diagnosis

\begin{tabular}{llll}
\hline & $\begin{array}{l}P M R^{\star} \\
(n=65)\end{array}$ & $\begin{array}{l}R A^{\star} \\
(n=19)\end{array}$ & $p$ Value \\
\hline Male/female & $20 / 45$ & $7 / 12$ & NS \\
Mean age (years) & 70.1 & 68.8 & NS \\
Fever & 23 & 4 & NS \\
Weight loss & 25 & 2 & 0.02 \\
Morning stiffness $>$ 1 hour & 47 & 15 & NS \\
Proximal muscular atrophy & 1 & 3 & 0.03 \\
Headache & 15 & 4 & NS \\
Peripheral synovitis & 17 & 15 & $0.0001 \dagger$ \\
\hline
\end{tabular}

^PMR = Polymyalgia rheumatica RA $=$ rheumatoid arthritis NS $=$ not significant.

$\mathrm{tp}<0.002$ after Bonferroni's correction.

Table 2 Main radiological and laboratory features in the two groups of patients, divided according to the final diagnosis

\begin{tabular}{llll}
\hline & $P M R^{\star}(n=65)$ & $R A^{\star}(n=19)$ & $p$ Value \\
\hline Erosions (plain standard radiograph) & 0 & 0 & $\mathrm{NS}^{\star}$ \\
ESR $^{\star}(\mathrm{mm} /$ / st hour) (mean) & 74.9 & 83.6 & $\mathrm{NS}$ \\
Rheumatoid factor (No of positive patients) & 8 & 7 & 0.03 \\
Rheumatoid factor (titre) & $92(32-424)$ & $98(40-820)$ & $\mathrm{NS}$ \\
Alkaline phosphatase and/or $\gamma \mathrm{GT}^{\star}$ increase & 16 & 1 & 0.1 \\
AST $^{\star}$ and/or ALT increase & 2 & 1 & $\mathrm{NS}$ \\
$\mathrm{WBC}^{\star}>10 \times 10^{9} / 1$ & 15 & 2 & $\mathrm{NS}$ \\
$\mathrm{PLT}^{\star}>450 \times 10^{9} / 1$ & 11 & 1 & $\mathrm{NS}$ \\
Haemoglobin $<105 \mathrm{~g} / 1$ & 10 & 1 & $\mathrm{NS}$ \\
$\% \mathrm{CD} 8($ mean $(\mathrm{SD})) \dagger$ & $28(7)$ & $31(9)$ & $\mathrm{NS}$ \\
\hline
\end{tabular}

${ }^{\star}$ PMR $=$ Polymyalgia rheumatica; RA = rheumatoid arthritis; NS = not significant; ESR = erythrocyte sedimentation rate; $\mathrm{GT}=$ glutamyltransferase; $\mathrm{AST}=$ aspartate aminotransferase; $\mathrm{ALT}=$ alanine aminotransferase , WBC $=$ white blood count; PLT $=$ platelet count

†Limited to 49 patients (39 PMR and 10 RA).
As multiple comparisons were performed, the Bonferroni adjustment was applied. ${ }^{15}$ The percentage of patients with persistent PMR or who developed RA during the follow up was calculated by the log rank test. ${ }^{16}$

\section{Results}

DIAGNOSIS AND FOLLOW UP

At first examination, a diagnosis of RA was made in 22/116 (19\%) patients, who were excluded from further study. An initial diagnosis of PMR was made in the remaining 94/116 $(81 \%)$ patients who were followed up for 12 months. During this period, three patients developed a malignancy (gastric cancer, lung cancer, lymphoma), three developed clinical and histological signs of giant cell arteritis, and four were lost to follow up (fig 1). A total of 84 patients was therefore evaluable after 12 months. A good initial response to prednisone was seen in all these patients despite occasional flare ups of the symptoms or the involvement of additional joints in 25 patients. In 19 of these 25 patients, the diagnosis was changed to RA because the ACR criteria were now fulfilled. In the remaining six patients with flare ups, the diagnosis of PMR was confirmed. In this last group, an increase in prednisone dose up to the last previous dose led to a complete clinical and serological recovery. Therefore the final diagnosis was RA in 41 patients (22 at first examination and 19 during the follow up) and PMR in 65 patients. Figure 2 shows the curve of the patients maintaining their diagnosis of PMR over the follow up period and the time when the diagnosis of RA was made.

\section{PRESENTING FEATURES}

Patients with RA diagnosed at the first examination (22 patients) were not considered for the evaluation of presenting features. As depicted in fig 1 , during the 12 months of follow up, 10 of 94 patients with an initial diagnosis of PMR were withdrawn from the study (four lost of to follow up and six for other diseases). Of the remaining 84 patients, 19 (23\%) developed RA during the follow up, and 65 (77\%) maintained the diagnosis of PMR.

These two groups were similar for age, sex, and inflammation indices (tables 1 and 2). Weight loss was more often observed in patients with a final diagnosis of PMR, whereas proximal muscle atrophy and peripheral synovitis were more common in patients with RA. However, after correction for multiple comparisons, only the presence of peripheral arthritis remained significantly different between the two groups. Arthritis was present in $17 / 65$ (26\%) patients with PMR and in 15/19 $(79 \%)$ patients with RA (adjusted $\mathrm{p}<0.002$ ) (table 1). However, this clinical feature has a poor positive predictive value, as only 15 out of $32(47 \%)$ patients with peripheral arthritis developed RA. Of the laboratory tests, only IgM RF positivity was more common in patients with RA than in patients with PMR, but this difference disappeared after Bonferroni's correction; RF titre was also similar in the two groups of patients. 
No significant differences were observed for the other laboratory variables including CD8 lymphocyte percentage, which was evaluated in a subset of 49 patients (39 PMR and 10 RA).

\section{Discussion}

Since Bagratuni's first description of PMR, ${ }^{17}$ similarities between this condition and RA have been described. Several studies have shown that RA can be diagnosed in $6-17 \%$ of patients initially classified as PMR and followed up for three to five years. ${ }^{141819}$ On the other hand, it is well known that a usually seronegative subset of elderly onset RA may show a PMR-like onset with prevalent involvement of the girdles, high ESR values, and good response to low dose steroid treatment. ${ }^{122021}$ Moreover, inflammatory involvement of peripheral joints and/or tenosynovial structures is described in a high proportion of patients with PMR. ${ }^{52}$ The demonstration that PMR is a synovitis by arthroscopic biopsy and ultrasonography of the shoulder joints may provide an explanation for such observations. ${ }^{123-25}$ However, the similarity and possible overlap in the presenting features of PMR compared with elderly onset RA has been the subject of some debate.

In our study we prospectively examined patients presenting with PMR-like onset. We noted that in 22 of these patients (19\%), a diagnosis of RA was possible at the first examination, and in an additional 19 patients a diagnosis of RA was confirmed over a 12 month follow up. As a result, of 116 patients examined because of PMR-like symptoms at onset, 41 $(35 \%)$ had RA or developed it within one year. The diagnosis of PMR was confirmed in 65 $(56 \%)$ cases. In contrast, Bahlas and coworkers found RA subsequent to the diagnosis of PMR in only $17 / 149$ patients $(11 \%) .{ }^{4}$ This discrepancy may be due to the retrospective design of their study. In addition, these authors found cancer in four $(2.6 \%)$ of their patients, a low frequency confirmed in our study (3/116; $2.6 \%)$.

Whether PMR and RA with a PMR-like onset are the same disease, or if some differences exist that could be helpful in the differential diagnosis is still a matter of debate. To investigate this topic further, we compared among patients satisfying at presentation the commonly used criteria for the diagnosis of $\mathrm{PMR}^{14}$ those with persistent PMR and those in whom RA developed during the follow up. The only significant difference between the two groups was the more common involvement of peripheral joints in patients with RA. However, this difference seems to be of poor clinical value, because peripheral arthritis was present in $15 / 19(79 \%)$ patients with RA but also in $17 / 65$ (26\%) patients with PMR. The last figure is very similar to that recently reported by Salvarani and coworkers for 177 Italian patients with PMR $^{5}$ and Gran and Myklebust in a prospective study from South Norway. ${ }^{22}$ As a result, less than half of the patients with girdle involvement and peripheral synovitis can be expected to develop RA after an initial diagnosis of PMR. The importance of a low percentage of CD8 T lymphocyte before treatment in distinguishing PMR and RA at disease onset has been reported by Corrigal and coworkers. ${ }^{10}$ Our data also showed a lower CD8 cell count in patients with PMR in comparison with patients with RA. The usefulness of this test for differential diagnosis cannot be confirmed because the values obtained in the two groups of patients were largely overlapping. Geographical differences may partially account for this difference because our data are very similar to those reported by Boiardi and coworkers for patients with PMR and RA from another location in Northern Italy. ${ }^{26}$

As expected, RF positivity was more common in patients with RA than in patients with PMR. However, this difference was not statistically significant. The high prevalence of RF positivity in our patients with either PMR or RA with PMR-like onset, usually described as seronegative diseases in other series, is surprising. Epidemiological studies on RF prevalence in the Italian population are lacking. However, environmental and/or genetic factors leading to a high rate of RF positivity in the Italian population exist. For example, hepatitis $\mathrm{C}$ virus infection, with or without mixed cryoglobulinaemia, is a potent inducer of RF production by plasma cells. ${ }^{27}$ The prevalence of antibodies to hepatitis $\mathrm{C}$ virus in the Italian general population is between $3.2 \%$ and $12.6 \%,{ }^{28}$ and can reach $40 \%$ among elderly subjects of certain Italian regions. ${ }^{29}$

The evaluation of new diagnostic tools such as antibodies against putatively citrullinated antigens (SA filaggrin, CCP) could be of interest in this subset of patients, even though their predictive value in seronegative RA appears to be $l^{30}{ }^{30}$; studies on this topic are warranted.

Several other clinical and laboratory variables have been suggested as useful in the differential diagnosis between PMR and RA with PMR-like onset. These include scintigraphic evaluation of the shoulder, ${ }^{8}$ thrombocytosis, ${ }^{31}$ serum cytidine deaminase, ${ }^{11}$ and antibodies to laminin B2 protein. ${ }^{32}$ However, all these observations need further confirmation and none of them is usually used in clinical practice.

On the other hand, HLA typing does not seem to allow early differentiation between RA and PMR. ${ }^{33}$

We are aware that a one year study does not allow us to draw definite conclusions. Notwithstanding, the data from this prospective study appear of some interest, in that about $35 \%$ of patients presenting with symptoms resembling PMR actually have or will develop RA during 12 months of follow up. More interestingly, when considering only patients with an initial diagnosis of PMR, more than $20 \%$ will develop overt RA during the follow up. At present, there are no clinical or routine laboratory features allowing early differentiation between these patients and patients with persisting PMR. 
1 Deal CL, Meenan RF, Goldenberg DL, Anderson JJ, Sack B, Pastan RS, et al. The clinical features of elderly-onse rheumatoid arthritis. Arthritis Rheum 1985,28:987-94.

2 Healey LA, Sheets PK. The relation of polymyalgia rheumatica to rheumatoid arthritis. J Rheumatol 1988;5 $750-2$

3 Al-Hussaini AS, Swanell AJ. Peripheral Joint involvement in polymyalgia rheumatica: a clinical study of 56 cases. Br J Rheumatol 1985;24:27-30.

4 Bahlas S, Ramos-Remus C, Davis P. Clinical outcome of 149 patients with polymyalgia rheumatica and giant cell arteritis. J Rheumatol 1998;25:99-104.

5 Salvarani C, Cantini F, Macchioni P, Olivieri I, Niccoli L, Padula A, et al. Distal musculoskeletal manifestations in polymyalgia rheumatica: a prospective follow-up study. Arthritis Rheum 1998;41:1221-6.

6 Healey LA. Polymyalgia rheumatica and seronegative rheumatoid arthritis may be the same entity. J Rheumatol 1992; 19:270-2.

7 Cid MC, Ercilla G, Vilaseca J, Sanmarti R, Villalta J, Ingelmo $\mathrm{M}$, et al. Polymyalgia rheumatica: a syndrome associated wit.

8 Hantzschel H, Bird HA, Seidel W, Kruger W, Neumann G, Schneider G, et al. Polymyalgia rheumatica and rheumatoid arthritis of the elderly: a clinical, laboratory, and scintigraphic comparison. Ann Rheum Dis 1991;50:619-22.

9 Combe B, Sany J, Le Quellec A, Clot J, Eliaou JF. Distribution of HLA-DRB1 alleles of patients with polymyalgia rheumatica and giant-cell arteritis in a mediterranean population. J Rheumatol 1998;25:94-8.

10 Corrigal VM, Dolan AL, Panayi GS. The value of percentage of CD8+ $\mathrm{T}$ lymphocyte levels in distinguishing polymyalgia rheumatica from elderly rheumatoid arthritis. J Rheumatol 1995;22:1020-4

11 Kassimos D, Kirwan JR, Kyle V, Hazleman B, Dieppe P. Cytidine deaminase may be a useful marker in differentiating elderly-onset rheumatoid arthritis from polymyalgia ing elderly-onset rheumatoid arthritis from polymyalgia 13:641-4.

12 Lange U, Teichmann J, Stracke H, Bretzel RG, Neeck G. Elderly onset rheumatoid arthritis and polymyalgia rheumatica: ultrasonographic study of the glenohumeral joints. Rheumatol Int 1998;17:229-32.

13 Arnett FC, Edworthy SM, Bloch DA, McShane DJ, Fries $\mathrm{JF}$, Cooper NS, et al. The American Rheumatism Association 1987 revised criteria for the classification of rheumatoid arthritis. Arthritis Rheum 1988;31:315-24.

14 Jones JG, Hazleman BL. Prognosis and management of polymyalgia rheumatica. Ann Rheum Dis 1981;40:1-9.

15 Cupples LA, Heeren T, Schatzkin A, Colton T. Multiple testing of hypotheses in comparing two groups. Ann Intern Med 1984;100:122-9.

16 Peto R, Pike MC, Armitage P, Breslow NE, Cox DR, Howard SV, et al; Design analysis of clinica trials requiring a prolonged observation of each patient. Br J Cancer 1977; 35:1-39.

17 Bagratuni L. Prognosis in anarthritic rheumatoid syndrome. Br J Rheumatol 1963;1:513-18.

18 Healey LA: Long term follow-up of polymyalgia rheumatica: evidence for synovitis. Semin Arthritis Rheum $1984 ; 13: 322-8$
19 Chuang TY, Hunder GG, Ilstrup DM, Kurland LT Polymyalgia rheumatica: a 10-year epidemiologic and clinical study. Ann Intern Med 1982;97:672-80.

20 Healey LA. Polymyalgia rheumatica and the American Rheumatism Association criteria for rheumatoid arthritis. Arthritis Rheum 1983;26:1417-18.

21 Van Schaardenburg D, Breedveld FC. Elderly-onset rheumatoid arthritis. Semin Arthritis Rheum 1994;23:367-78.

22 Gran JT, Myklebust G. The incidence and clinical characteristics of peripheral arthritis in polymyalgia rheumatica and temporal arteritis: a prospective sudy of 231 cases. Rheumatology 2000;39:283-7.

23 Douglas WA, Martin BA, Morris JH. Polymyalgia rheumatica: an arthroscopic study of the shoulder joint. Ann Rheum Dis 1983;42:311-31.

24 Chou CT, Schumaker HR. Clinical and pathologic studies of synovitis in polymyalgia rheumatica. Arthritis Rheum $1984 ; 27: 322-7$

25 Meliconi R, Pulsatelli L, Melchiorri C, Frizziero L, Salvarani C, Macchioni $\mathrm{P}$, et al. Leukocyte infiltration in synovial tissue from the shoulder of patients with polymyalgia rheumatica. Arthritis Rheum 1996;39:1199polym.

26 Boiardi L, Salvarani C, Macchioni P, Casadei Maldini M, Mancini R, Beltrandi E, et al. CD8 lymphocyte subsets in active polymyalgia rheumatica: comparison with elderlyonset and adult rheumatoid arthritis and influence of prednisone therapy. Br J Rheumatol 1996;35:642-8.

27 Ferri C, Greco F, Longombardo G, Palla P, Moretti A, Marzo E, et al. Hepatitis $\mathrm{C}$ virus antibodies in mixed cryoglobulinemia patients. Arthritis Rheum 1991;34: 1606-10.

28 Chiaramonte M, Pupo A, Menegon T, Baldo V, Malatesta R, Trivello R. HBV and HCV infection among nonEuropean Union immigrants in North-East Italy. Epidemiol Infect 1998;121:179-83.

29 Osella AR, Sonzogni L, Cavallini A, Foti L, Guerra V, DiLeo A, et al. Molecular epidemiology of hepatitis $\mathrm{C}$ virus infection in an area of hyperendemicity in southern Italy: a population based study. J Clin Microbiol 1999;37:2371-2.

30 Goldbach-Mansky R, Lee J, McCoy A, Hoxworth J, Yarboro C, Smolen JS, et al. Rheumatoid arthritis associated antibodies in patients with synovitis of recent onset. Arthritis Res $2000 ; 2: 236-43$

31 Harten P, Seyfarth B, Loffler H. Thrombocytosis in polymyalgia rheumatica: an additional criterion and possible risk factor for ischemic complications? Arch Intern Med 1998;158:95-7.

32 Brito J, Biamonti G, Caporali R, Montecucco C. Autoantibodies to human nuclear lamin B2 protein: epitope specificity in different autoimmune diseases. J Immunol 1994; 153:2268-77.

33 Gonzales-Gay MA, Hajeer AH, Dababneh A, Makki R, Garcia-Porrua C, Thomson W, et al. Seronegative rheumatoid arthritis in elderly and polymyalgia rheumatica have similar patterns of HLA association. J Rheumatol 2001; 28: $122-5$. 